\title{
A socioeconomic analysis of commuting professionals
}

\author{
Moritz Kersting $^{1,5} \cdot$ Eike Matthies $^{2,3} \cdot$ Jörg Lahner $^{3} \cdot$ Jan Schlüter ${ }^{4,5}$ (D)
}

Published online: 17 August 2020

(c) The Author(s) 2020

\begin{abstract}
Everyday commuting as a mobility phenomenon is well-investigated and has been the topic of many contributions. Nevertheless, the distinct determinants of the commuting professional's motivation to regularly travel comparably long distances have not been in the focus of research yet. Thus, this contribution analyses the sociodemographic variables that underpin the well-educated group's decision to commute longer distances than other educational groups. For German Microcensus data, ordered logistic regression models are used to estimate and compare the influences of sociodemographic variables on all commuting employees and commuting professionals. The data of German Microcensus of the year 2012 are used for the analysis. The results imply that some characteristics exert the already known effects on both samples. Others do vary with education and thus illustrate some unique sociodemographic influences on the commuting behaviour of professionals.
\end{abstract}

Keywords Commuting · Professionals · Education · Occupation · Microcensus · Germany

\section{Introduction}

Occupational mobility is undergoing continuous and long-run changes. The impacts of digitisation, an increase of knowledge-intensive activities and changes in sociodemographic patterns reduce the dependence of residential and workplace choice especially for professional workers (Alexander and Dijst 2012; Strambach and Kohl 2015; Kakihara and Sørensen 2004; He and Hu 2015). Hence, the average commuting distance throughout

Jan Schlüter

jan.schlueter@ds.mpg.de

1 Chair of Statistics, Department of Economics, Georg-August-University of Göttingen, Humboldtallee 3, 37073 Göttingen, Germany

2 Department of Economics, Georg-August-University of Göttingen, Humboldtallee 3, 37073 Göttingen, Germany

3 Chair of Economic Development and Corporate Governance, Faculty of Resource Management, Hochschule für angewandte Wissenschaft und Kunst, Büsgenweg 1a, 37077 Göttingen, Germany

4 Institute for the Dynamics of Complex Systems, Faculty of Physics, Georg-August-University of Göttingen, Friedrich-Hund-Platz 1, 37077 Göttingen, Germany

5 NGM, Department of Dynamics of Complex Fluids, Max-Planck-Institute for Dynamics and SelfOrganization, Am Fassberg 17, 37077 Göttingen, Germany 
Europe increased over the last years (Einig and Pütz 2007; Barker and Connolly 2006; Haas and Hamann 2008; Aguilera 2005; Eurostat 2019; Ruppenthal and Lück 1999).

From the labour demand's perspective, this increased mobility provides new opportunities to face several challenges of the new century. The impact of contemporary and future problems on the labour markets such as a shortage of skilled professionals, the rural exodus or demographic changes can be mitigated by enabling suitable surplus labour to move fast and easy from one region to another (Shearmur and Motte 2009; Granato et al. 2009; Epifani and Gancia 2005; Suedekum 2005).

Then again, several problems arise from increased mobility. Phenomena such as air pollution, climate change induced by greenhouse gas or congestion are common knowledge and often associated with motorised individual transport (Nobis and Kuhnimhof 2018). Moreover, spatial mismatches in terms of job-housing imbalances or the commuters' access to certain means of transport are determined by factors such as housing-prices, neighbourhoods, segregation or growing sprawls (Ewing et al. 2003; Horner and Mefford 2007; Zhu et al. 2019; Sultana 2002, 2005).

Thus, the task of policy and decision-makers is to provide green, fair and appropriate infrastructural frameworks that vary by region and the corresponding user-groups' characteristics. Next to new technological opportunities in terms of smart, connected and green mobility, a deep understanding of the determinants of an individuals' mobility demand is indispensable.

As previous research suggests, contemporary changes in individual commuting patterns are determined by several social, economic and geographic characteristics such as age, gender, place of residence, type of settlement, workplace choice, income or qualification (Wagner and Mulder 2015; Auspurg and Schönholzer 2013; Sultana 2002; Weber and Sultana 2008; Granato et al. 2009; Ewing et al. 2003). Moreover, the presence of other household members such as a partner or children and their characteristics seem to exert an interdependent influence on an individual's commuting behaviour (Auspurg and Schönholzer 2013; Sultana 2003, 2005; Surprenant-Legault et al. 2013; Wagner and Mulder 2015; Vuk et al. 2016; Hjorthol and Vågane 2014; Green 1997).

By several interdisciplinary contributions, numerous phenomena were found to be related or interdependent to the transitions in the job-related mobility of employees. From a medical perspective, commuting has a clear negative effect on the health of an individual. Stress and time pressure are common proxies to measure the impact of commuting on the prevalence of diseases such as high blood pressure and psychological problems (Evans and Wener 2006; Gottholmseder et al. 2009). The results of e.g. Roberts et al. (2011), Clark et al. (2019) and Rüger and Schulze (2016) indicate that the health of women, in particular, is negatively affected by commuting. As the presence of children in the household reinforces the effect, the difference is explained by the often more complex everyday life of women, which tends to involve longer trip chains, e.g. due to the escorting of children (Scheiner and Holz-Rau 2017; Motte-Baumvol et al. 2017; Oakil et al. 2016).

Many further implications on the connection of mobility and gender emerge from the social sciences. Gender-specific role models, differences in occupational choice, income and family structures have already been validated as both cause and symptom of the divergent mobility patterns of women and men by numerous contributions (Auspurg and Schönholzer 2013; Manderscheid 2016; Hjorthol and Vågane 2014; Wagner and Mulder 2015; Augustijn 2018; Rapino and Cooke 2011). Nevertheless, there is evidence, that these differences dilute under certain circumstances (Sultana 2005).

Economic themes in literature mainly consider sociodemographic characteristics such as qualification, family structure and gender as an explanation for an employee's commuting 
behaviour (Pfaff 2012; Manderscheid 2016; McQuaid and Chen 2012). Moreover, residential and workplace choices of employees were found to be dependent on the attributes of a region, such as unemployment, wage levels, housing prices or the economic structure (Swärdh and Algers 2016; Roberts et al. 2011; Shearmur and Motte 2009; Reichelt and Haas 2015; Zhu et al. 2019). Specific entanglements appear to exist between urban and rural areas (Sultana 2003; Champion 2009; Renkow and Hoover 2000; Bosworth and Venhorst 2018) as well as regions with differences in economic prosperity like West and East Germany (Bosworth and Venhorst 2018; Einig and Pütz 2007; Granato et al. 2009; Reichelt and Haas 2015; Haas 2012). Urban structure and the spatial distribution of socioeconomic properties form individual commuting patterns on a micro-level and thus influence the extent and efficiency of local transportation capacities (Horner et al. 2015; Kanaroglou et al. 2015; Zhou and Murphy 2019; Layman and Horner 2010).

Whilst the effects of income on occupational mobility have been extensively discussed in the literature, an employee's qualification was usually used as a control. Contributions such as Granato et al. (2009), Groot et al. (2012), Wrede (2013), Kakihara and Sørensen (2004) and Alexander and Dijst (2012) suggest an impact of education on residential location choice and thus commuting distances on both the household and individual level. Moreover, these patterns appear to vary with different economic and sociodemographic characteristics and along qualification groups (Granato et al. 2009; Groot et al. 2012; Wrede 2013; Sandow 2014).

To complement previous research, this contribution aims to analyse the sociodemographic determinants on the commuting behaviour of professionals. The results for highly skilled employees are compared with the entirety of workers to emphasise the dedicated effects. The basis for the analysis is the German Microcensus of 2012, which covers a large number of respondents and attributes and hence allows to examine specific strata in detail.

The analysis proceeds as follows. The subsequent section provides an overview of the current state of research regarding the links between commuting and the economic, spatial and sociodemographic characteristics of employees. This overview is followed by the third section, in which assumptions regarding the commuting behaviour of high-skilled workers are formulated based on the presented theories and approaches. Subsequently, the results of several ordered logistic regression models are presented and discussed.

\section{Determinants and effects of commuting: a brief review of the literature}

A considerable amount of literature examined the complex and interdependent determinants and effects of commuting and used a variety of definitions and assumptions. One straight approach defines all employees as commuters, that recurrently travel between home and work. By that, almost all employees can be counted as commuters (Wagner and Mulder 2015). Additional restrictions such as certain travel time or the commuting distance are often used to achieve a finer distinction, e.g. $2 \mathrm{~h}$ per day (Schneider et al. 2002), $1 \mathrm{~h}$ one-way (Kley 2012) or 30 km one-way (Sandow 2014). Reichelt and Haas (2015) defined those employees as commuters, whose residence is located in another county than the place of work. Beyond prominent characteristics such as income or education, behavioural approaches use measures like an individual's stated willingness to commute or the valuation of the time of other household members to explain the more complex dynamics within household (Swärdh and Algers 2016). This section provides an overview of the common approaches and findings of the determinants of commuting. 


\section{Income, education and commuting}

In several European regions, the importance of job-related mobility is increasing in absolute numbers (Eurostat 2019). For Germany, the amount of job-related passenger-kilometres increased by roughly $9 \%$ and represents a share of more than $20 \%$ of the total mobility (Nobis et al. 2019). The findings of the German Mobility Panel suggest that the commuting distances are especially high for households with high education and high-income (Nobis and Kuhnimhof 2018).

In a simplified economic model, travelling (and thus commuting) causes monetary and non-monetary costs. While expenditures e.g. for fuel, tickets or vehicles account for the first group, the second group contains other consequences such as negative health effects or time costs. From an economic perspective, an employee's income influences commuting behaviour in several ways. First, the income determines the amount of money, that can be spent on commuting. Second, it provides compensation for negative non-monetary effects.

The impact of monetary costs on commuting behaviour is comparably simple to assess. For instance, DeLoach and Tiemann (2012) explains variances in the number and behaviour of job-related car-drivers from the American Time Use Survey by internalising corresponding gasoline prices. High gasoline prices led to a decline in the number of drivers and induced fuel-efficient driving. It is reasonable to assume that employees seek to reduce not only monetary but also non-monetary costs e.g. by their mode choice or by pooling their rides with colleagues (Gardner and Abraham 2007; Ferguson 1997). In the case of carpooling, Buliung et al. (2010) found that saving money was no extraordinary incentive for US and Canadian employees to share their rides to travel to work. Other factors, such as a desire for socialising, reduced stress or environmental consciousness are suggested to play an important role (Buliung et al. 2010; Ettema et al. 2012). In several countries, these commuting behaviours are the target of policy measures. Taxes, subsidies and promotion of certain transport systems are used to stimulate a certain behaviour, primarily to reduce traffic jams and negative environmental effects (Vanoutrive et al. 2012; Potter et al. 2006).

Occupations carried out by better qualified and specialised workers are usually better paid. Also, wages for knowledge and skill intensive work vary regionally much more than wages for other jobs. This induces a higher ability to bear the monetary costs of commuting, inducing more flexible behaviour in the choice of residence and job-location of skilled workers (Haas 2012; Groot et al. 2012; Sultana 2002). Furthermore, with increasing specialisation, it becomes more unlikely to find a job in the immediate vicinity that matches the individual qualification profile. There are several indications that the mobility behaviour of highly qualified employees differs fundamentally from that of others, e.g. in terms of the commuting distances (e.g. Dauth and Haller 2018; Groot et al. 2012; Haas and Hamann 2008) or avoidance strategies such as weekend commuting (Rüger and Sulak 2017).

Whilst these basic economic mechanisms of commuting are widely understood, more complex questions arise when they relate to other disciplines and approaches. At a glance, the current state of research suggests occupational commuting to be embedded in an interdependent and multidisciplinary framework.

\section{Commuting and life satisfaction}

A row of contributions deals with the relationship between life satisfaction and work-related mobility (see De Vos et al. 2013 for a comprehensive literature review). Life satisfaction is 
usually determined by surveys and represented by indicators or proxies. These analyses on physiological and psychological well-being investigate the effects of occupational mobility on the health of employees. Dissatisfaction, psychological pressure and other stresses were identified as the common proxies by which mobility harms health and thus decreases a persons life satisfaction (Rüger and Schulze 2016; Clark et al. 2019; Stutzer and Frey 2008; Chatman et al. 2019). Moreover, occupational mobility causes temporal and monetary costs. According to pure economic equilibrium theory, such negative effects of commuting should be compensated by positive effects like a better job match or a higher income (Pfaff 2014; Stutzer and Frey 2008). However, the literature mentioned above suggests that these costs and benefits usually do not meet in the end and employees commute longer than expected. To improve their travel satisfaction, employees would have to relocate their place of work or residence (see Morris and Zhou 2018 for an exceptional case).

Based on the data of the German Socio-Economic Panel, Pfaff (2014); Stutzer and Frey (2008) and Stutzer and Frey (2007) demonstrate, that the general life satisfaction decreases with increasing commuting distances. Moreover, the findings of De Vos et al. (2019) suggest higher travel satisfaction after a relocation that comes along with shorter travel distances. Nevertheless, in practice, numerous employees travel longer times and distances than optimal and avoid relocation (Stutzer and Frey 2008; Ye et al. 2020). Thus, the nonmonetary costs caused by long commuting distances are not sufficiently compensated by e.g. income-related effects. This economic mismatch, or rather commuting paradox (Stutzer and Frey 2008) arises from several individual restrictions, such as family ties or the high costs for relocating a workplace or residence (Ye et al. 2020; Stutzer and Frey 2007, 2008; Pfaff 2012; Chatman et al. 2019; Clark et al. 2019; Morris and Zhou 2018).

Nevertheless, especially professionals appear to benefit from the rise of information and communication technologies as knowledge-intensive work becomes more flexible in spatial, temporal or interaction patterns and can be adapted to household restrictions more easily, by means such as home office or working while commuting (Alexander and Dijst 2012; Ettema et al. 2012; Kakihara and Sørensen 2004; He and Hu 2015; Clark et al. 2019).

\section{The influence of family and gender}

On an individual level, longer commuting distances lead to a higher income as the number of better-paid jobs increases with a workers' search radius. These higher incomes can be interpreted as compensation for higher travel expenses (Pfaff 2012; Stutzer and Frey 2007; Swärdh and Algers 2016; Scheiner 2016). In the economic literature, it is also common practice to explain commuting behaviour with spatial analyses. The individual choice of residence and place of work depends on several trade-offs between factors such as rentlevels, income, commuting stress and school- or residential quality. A combination of residence- and workplace location with a resulting commuting distance is chosen in theory, if it maximises the benefit under all individual constraints (Borck and Wrede 2006; Einig and Pütz 2007; Pfaff 2012; Reichelt and Haas 2015; Wrede 2013; Chatman et al. 2019; Sultana 2002).

Regarding the family context, previous research has focused on the joint location (and thus commuting) decisions of couple households or families with children (Hjorthol and Vågane 2014; Stutzer and Frey 2007; Green 1997; Manderscheid 2016; Pfaff 2012; Sultana 2005; Surprenant-Legault et al. 2013). It was observed with a few exceptions (see below) that commuting distances increase with the size of the household. An educated presumption is based on increasing migration costs with each additional household member, so 
that long-distance commuting often is the best strategy for individual household members (Pfaff 2012). Another viable explanation is that each additional household member adds more restrictions on the households common residence and workplace choices.

One can expect that couples (and thus families) as a joint household will optimise their overall benefit when making location decisions (Stutzer and Frey 2007; Sultana 2005) and that the person with the higher income or the higher local commitment will dominate the choice of location (Green 1997). Auspurg and Schönholzer (2013) illustrate that the lower commuting distances of women contribute to a lower income. An increase in the commuting distance of women on average also resulted in an increase in income, which can be explained by a larger selection of jobs due to an increased search radius. No significant increase was reported for men.

Among others, Scheiner (2016), McQuaid and Chen (2012), Hjorthol and Vågane (2014) and Manderscheid (2016) use and summarise interdisciplinary approaches to explain gender divergence, including theories of economics, sociology and gender studies. A fundamental change in the classic mobility strategies of men, women and joint households can be observed due to a steadily rising female employment rate and changing employment patterns in developed countries (Pfaff 2012; Kümmerling 2015). Summarising previous contributions, women work more often part-time than men, earn less and therefore show on average less willingness or ability to commute. It has also been observed that women in (hetero) couple relationships primarily take on family tasks such as housework and childcare. As a result, their willingness to commute decreases and the selection of well-paid jobs that match their qualification and specialisation decreases as well as (Augustijn 2018; McQuaid and Chen 2012; Kümmerling 2015; Swärdh and Algers 2016; Scheiner 2016; Gutierrez 2018). Consistently, Scheiner and Holz-Rau (2017) found by analysing German activity patterns that women's travel behaviour (despite shorter travel distances) is comparably more complex and efficient. This finding gives support to the general theory of traditional role models with "male breadwinners" who work full time and commute far, and "female housewives" conducting a variety of activities during the day.

Swärdh and Algers (2016) analysed survey data from the Stockholm region based on a stated choice approach. Their findings give support to the theory of role models as an explanation for the observed divergence in commuting distances. The main results are that both spouses value the woman's commuting time higher than the mans'. Thus, both would prefer the man to commute longer distances than the woman.

Pfaff (2012) showed by using German Socioeconomic Panel data that, for Germany, the number and the age of children influence the distance travelled by the parents. Again, divergence by gender can be observed: While children have a negative effect on women's commuting distances, they seem to influence men's behaviour in the opposite direction. The effects are less striking for older children. In summary, children increase the probability for men to commute and decrease the probability for women, especially those working part-time (McQuaid and Chen 2012).

Nevertheless, Sultana (2005) and Surprenant-Legault et al. (2013) found for the NorthAmerican metropolitan areas of Atlanta and Montreal, respectively, that the average commuting times of dual-earner household are below the commuting times of single-earner households. Surprenant-Legault et al. (2013) found the influence of one partners' commuting distance on the others' to be significantly positive. Thus, partners in dual-earner households were found to rather complement than to substitute each others commuting distances, which is inconsistent with the findings mentioned above. When testing for gender differences, both wives and husbands of dual-earner households were found to travel shorter distances than their counterparts from single-earner households (Sultana 2005). Moreover, 
one conclusion of the analyses is, that higher housing prices in proximity to the workplaces exert a more striking impact on the commuting behaviour than sociodemographics.

In general, the overall negative but non-homogeneous impact of children on their parents commuting distances is usually explained with the family members' wish to spend time together. During the ACTUM-project, scientists analysed activity-based travel chains and their relation to the individual and mobility demand in Copenhagen (Wind 2012). Using this data, Vuk et al. (2016) determined the influence of socioeconomic variables and the household structure on general travel demand. One of their major findings is that the presence of children increases the priority of family time and that this dependency seems to be stronger with a younger age of the children. Their results support the more general findings of a row of contributions such as Hjorthol and Vågane (2014), Swärdh and Algers (2016), Pfaff (2012) and McQuaid and Chen (2012).

In short, gender-related research on occupational mobility suggests both the existence of reinforcing path dependencies on an economic level and a strong impact of traditional role models on women's willingness and ability to commute.

\section{Commuting from an economic geographical perspective}

As described above, income and occupation can be assumed to exert an influence on an individual's residential choice and thus the commuting behaviour. Naturally, economic prosperity is not evenly distributed within a country. In the case of Germany, economic differences between the eastern and the western parts of the country are widely known and certain mobility dynamics can be assumed. Thus, several contributions have examined the commuting and migration between East and West Germany. Einig and Pütz (2007) illustrate that the commuting distances in the areas with weaker labour markets in eastern Germany are significantly higher than those in economically strong regions. A similar trend exists for the commuting duration, that seems to intensify in the long-term trend (Winkelmann 2010). Preferred destinations for long-distance commuters are primarily regions that are strong in economic terms. Since the German Reunification, a distinct mobility dynamic has established in absolute numbers from the east to the west, in terms of both migration and commuting (Granato et al. 2009; Haas and Hamann 2008; Brautzsch 2017; Haas 2012).

Contributions such as Granato et al. (2009), Epifani and Gancia (2005), Suedekum (2005) or Haas (2012) focus on regional economic perspective. Traditional economic explanations suggest that both commuting and relocation is useful for balancing regional labour-economic differences and smoothes regional differences in employment and wages. In this framework, relocation and commuting decisions of workers are motivated by low qualification-job fits or wages within a region. Thus, their mobility establishes new steady states on the labour markets by balancing the spatial mismatch. On the contrary, approaches of the New Economic Geography suggest that commuting and migration can also exacerbate existing disparities.

However, characteristic occupational mobility occurs between East and West Germany. The role of labour and housing market differences as the most important driving forces of commuting is generally acknowledged (Bogai et al. 2014; Shearmur and Motte 2009; Granato et al. 2009; Sultana 2005). Due to the emigration of workers from regions that are often weak in economic terms, a brain drain in the already weak regions is an obvious suggestion. Hence, several studies deal with the qualification level of commuters and migrants (Granato et al. 2009; Haas 2012). In a longitudinal analysis of German Socio-Economic 
Panel data, Granato et al. (2009) show that among East German commuters and emigrants, the smallest groups consist of the highly qualified workers and the largest of low-skilled workers. Occupational mobility into the West German labour market is primarily achieved by less qualified workers, while qualified workers are the dominant group in the opposite direction. In absolute terms, eastern Germany has a negative balance in each group, but the qualified segments are disproportionately less affected.

Since this fact contradicts the fundamental theories and empirical findings of mobile professionals outlined above, the case of Eastern Germany has not been understood definitely. It is not yet known whether Eastern Germany is affected by a sustained migration of talents to the West since the German Reunification. Although the migration and commuting balances of highly qualified workers are often negative, other levels of education are still much more affected. Hints for interdependence with sociodemographic characteristics e.g. for gender, family variables and age are stated in Haas (2012), Granato et al. (2009) and Haas and Hamann (2008).

Next to such macrogeographic implications on the level of states or regions, numerous contributions analysed spatial mismatches on a micro-scale. Several studies found urban form and network properties to contribute to mobility decisions and to be correlated with sociodemographic variables such as income (Schleith et al. 2016; Schleith and Horner 2014), family variables (Sultana 2005), life cycle stages (Horner et al. 2015; Kim et al. 2005; Wood et al. 2016) or (especially in North American contexts) minority background (Horner and Mefford 2007; Sultana 2005; Yang 2008). On a micro-scale, both individual and aggregated commuting patterns of workers are used to assess urban planning and transportation systems' efficiency. Excess commuting has established as one major concept in order to evaluate to which extent phenomena such as urban sprawl or segregation extend the daily commutes in a region (Kanaroglou et al. 2015; Horner et al. 2015; Korsu and Le Néchet 2017; Suzuki and Lee 2012; Zhou and Murphy 2019; Layman and Horner 2010).

As the preceding summary demonstrates, an employee's determinants of occupational mobility do not stand on their own but are embedded in an interdependent network of characteristics and relationships. Other attributes, such as gender or age, can also provide further explanatory content in all the categories mentioned. Thus, the following section sets up assumptions to conclude the theories and findings as described above.

\section{Theories and assumptions on the everyday commuting of professionals}

This contribution aims to evaluate the influence of economic, demographic and social variables on the commuting behaviour of professionals. As the state of research implies, these characteristics are embedded in an interdependent relational network. Following the findings of the previous research as described above, three subsets of assumptions are set up.

\section{Occupation}

The first part of this contribution analyses the impact of occupational variables on commuting behaviour. As shown above, there is a broad consensus in the literature, that income and commuting distance are positively correlated. On the one hand, higher income increases an employee's willingness to commute, as it compensates for higher costs and stress levels. On the other hand, employees with a higher commuting radius cover a larger area and by 
that a comparable higher number of attractive job vacations. While the positive correlation of income and distance turned out to be valid in general and especially for the middle-class or lower educated worker, the effect has to be evaluated separately for professionals, as their behaviour might underlie different constraints (Groot et al. 2012; Granato et al. 2009; Wrede 2013). Since a high qualification level usually comes along with a higher degree of specialisation, the distance to an appropriate job is likely to be higher compared to lowerskilled employees. On the other hand, low unemployment rates for professionals suggest a higher demand for skilled workers that could result in higher wages and lower distances necessary to achieve an appropriate job match. Further on, professionals are less likely to become unemployed than other groups of workers. In comparison, especially middle-class workers are suggested to accept very long commuting distances to maintain their income levels due to harder labour market conditions (Groot et al. 2012).

Assuming stress levels to increase with commuting distances and decreasing marginal utility of income, it can be expected that an individuals maximum commuting distance exists. Since the wages for higher qualified employees are usually higher than on average, a marginal increase of both income and commuting distance might result in lower overall utility. Thus, the willingness to commute long distances could be lower for highly qualified employees than on average. Thus, the first assumption is:

\section{A 1.1: The influence of income on the commuting distance of professionals is posi-} tive.

As shown above, commuting is a strategy to avoid expensive and inconvenient relocation. Thus, an employee only relocates if the costs of relocation are smaller in comparison to the costs of commuting. It can be assumed that employees with fixed-term contracts are more likely to choose commuting instead of relocation since they have to make new decisions when their contract ends. Besides, the negative effects of commuting such as stress might be less considered when they have to be endured only for a while. In comparison, part-time workers usually receive a lower wage than an equivalent full-time worker, regardless of their contracts' duration. Since their income cannot compensate for the negative effects of long commuting distances, their commuting times are comparably shorter.

\section{A 1.2: Professionals with fixed-term contracts commute longer distances than those with permanent contracts.}

\section{A 1.3: Part-time contracts exert a negative influence on commuting distances for all samples and genders.}

Managers and supervisors are usually better paid and more autonomous and independent in their work. Since their occupational characteristics are linked to other variables as mentioned above, this special group likely exerts a distinct commuting behaviour. According to McQuaid and Chen (2012), the commuting times of managers in the UK can be expected to be distinctly higher than those of regular workers. In contrast, Sultana (2005) found for employees in the Atlanta metropolitan area, that higher occupational status is linked to shorter commutes. Since their findings are based on different geographical areas, the comparability is somewhat limited. Due to the study design and the location of the research area, the resulting hypothesis for German employees is:

\section{A 1.4: Managers and supervisors commute longer distances than regular profession- als or employees.}




\section{Differences from the East to the West}

As the state of research implies, labour demand and wages differ from East Germany to West Germany. Although the indicators converge for several years, the western parts of the country have generally lower unemployment rates and higher wages (Haas and Hamann 2008; Haas 2012; Granato et al. 2009; Fuchs et al. 2015; Krause 2019). In accordance, it can be assumed that the commuting balance from the west to the east is positive and the other way round. Consistently, Granato et al. (2009) and Haas (2012) validate this assumptions for the years 2000-2005 and 1999-2010. However, Granato et al. (2009) observed that the share of highly qualified commuters from East to West is considerably smaller than for other qualification groups, although especially professionals are well known for their longer commuting distances as shown above. A viable economic explanation is that wage levels and labour demand for professionals vary by region.

By analysing commuting data of the German Labour Agency, Haas and Hamann (2008) concluded that highly qualified employees usually commute comparably longer distances. However, they noticed that this difference was not as distinct in East as in West Germany. On the one hand, their results go along with the theory, that higher wages induce higher commuting distances. On the other hand, their findings are contradictory to the assumption, that a weaker labour demand leads to higher commuting distances as professionals endeavour to find a job which is both better paid and second matching their specialised qualification. The assumption to check for an imbalance between East and West Germany is:

A 2.1: East German professionals do not commute as far as West German professionals. The effects are less pronounced for the entirety of employees.

\section{Commuting on household levels}

So far, the commuting behaviour of professionals was analysed on an individual level. As the state of research implies, location choices as a basis for commuting behaviour are made on the household level. Thus, additional household members such as children or partners translate into additional constraints, as different occupational or educational requirements have to be considered. The effects on men and women distinct due to divergent valuation of the spouses commuting time and role models (Vuk et al. 2016; Hjorthol and Vågane 2014; Swärdh and Algers 2016; McQuaid and Chen 2012).

From an exogenous perspective, a household which consists of a couple optimises its overall utility by choosing the location of residence and the places of work. Since the individual distance to work is not the only constraint to be considered, the resulting individual commuting times of couples should be longer than those of singles. Among others, the findings of e.g. Morris and Zhou (2018) and Pfaff (2012) gives support to this assumption but do not distinguish between educational groups.

From an endogenous perspective, household decisions are the result of bargaining. Previous analyses validated that the partner with the higher economic power is more likely to be the winner of bargaining decisions considering the location choice. In contrast, the other partner often acts as the households secondary earner, which can imply part-time work or a job change after a households' relocation. Hence, the partner with a lower income is usually more restricted in mobility decisions and has to adapt to the primary earner's preferences. Thus, the resulting commuting distances are usually shorter (Auspurg and 
Schönholzer 2013; Wagner and Mulder 2015; Hjorthol and Vågane 2014; Green 1997). On average, women receive lower wages than men and are often associated with traditional gender roles. Thus, they can be assumed to often take the role of the households' secondary earner, that adapts to the other partner's preferences.

As shown above, the overall effects of differences in income and education on commuting distances have already been in the focus of previous research. However, it has not been analysed so far whether the known mechanisms also apply within the group of professionals. Assuming a homogeneous skill-level within this group, the influence of different incomes on a households commuting behaviour has to be tested. Thus, the assumption is as follows:

A 3.1: A higher income of a male professional decreases the commuting distance of his (female) partner. Reversely, the influence of a female professional's income on her male partner is less striking. For the entirety of workers, the results are similar but more distinct.

As shown above, professionals are known to generally commute longer distances than regular workers. Both a higher salary and a more complex qualification profile have been identified by previous research as channels for this observation (Haas 2012; Groot et al. 2012; Dauth and Haller 2018; Haas and Hamann 2008; Rüger and Sulak 2017). Thus, professionals are associated with higher earnings and longer commutes.

A household with two working spouses has to solve more complex problems regarding joint location choice and individual commuting distances. On the one hand, both spouses aim to maximise the households joint income. On the other hand, they value to spend time with each other and potential children (Swärdh and Algers 2016). Moreover, non-occupational household tasks have to be performed, usually to a large share by women while men are associated with both a higher income and longer commuting distances (Augustijn 2018; McQuaid and Chen 2012; Kümmerling 2015; Scheiner and Holz-Rau 2017; Swärdh and Algers 2016).

The influence of a high qualified partner on a respondent's commuting behaviour is likely to vary with the respondent's qualification and income. The higher a spouse's qualification and thus expected income is, the higher is this spouse's optimal share in the contribution to the household income. Contrary, a lower educated spouse is more likely to perform unpaid but obligatory household tasks. In case that both partners are professionals with high education and a high expected income, comparably long commutes can be assumed for both spouses (Green 1997). To maintain a sufficient level of family time and housework, it is likely that bargaining between the spouses has either equal distances and shares of housework or separation of occupational work and household tasks, as a result, (Hjorthol and Vågane 2014; Scheiner and Holz-Rau 2017).

Gender differences have to be considered since Swärdh and Algers (2016) found both spouses to value women's commuting time higher. As summarised above, previous research suggests traditional "male breadwinner" and "female housewife" role models to be prevalent. Thus, the resulting assumption is:

A 3.2: The impact of the partner's education on a professional's commuting distance is negative. The effect is more striking for female professionals. The effects are less striking in the full sample.

The location and commuting choices of households that contain children are more complex. In general, an overall effect of children on the commuting behaviour of their parents is widely recognised (e.g. McQuaid and Chen 2012; Sultana 2005; Scheiner and Holz-Rau 
2017; Pfaff 2012; Vuk et al. 2016). It can be assumed that parents want to spend time with their children e.g. for education and nurturing (Vuk et al. 2016) so that the opportunity costs of commuting time increase with each child. Empirical finding (McQuaid and Chen 2012; Sayer et al. 2004; Hjorthol and Vågane 2014) suggest that this general theory is valid for women whose commuting times decline when they have children. In contrast, men with 1 to 3 children commute longer than those without children. Gender-related differences are usually derived from both sociological role models and economic dependencies such as income differences that induce different mobility behaviour as shown above. Thus, these differences might vary for different educational and occupational groups, as income, as well as role models, differ from other groups. Böhm et al. (2016) and Sayer et al. (2004) found occupational and educational variables evident to influence on the daily minutes of child care in four developed countries. In Germany, both lower-skilled and non-whitecollar employed mothers and fathers spent fewer minutes with their children. The effects turned out to be more striking for women than for men. Also for Copenhagen, the effect of education on the priority of family time is positive (Vuk et al. 2016), so that the opportunity costs of spending time with commuting increase for professionals. Hence, the assumption is:

\section{A 3.3: The commuting distance of women declines with a higher number of children, while men commute further. The effects are less pronounced for professionals.}

\section{Analysis and results}

\section{Data cleaning}

The following sections' analyses are based on data from the German Microcensus of the year 2012 (Forschungsdatenzentren der Statistischen Ämter des Bundes und der Länder (b) 2012), that represent the interviews of approx. 1\% of the German population (Forschungsdatenzentren der Statistischen Ämter des Bundes und der Länder (a) 2019). The 2012 version of the German Microcensus was chosen for the analysis since it contains a set of questions that deal with the individual commuting behaviour. More recent datasets do not contain these or other necessary attributes, as they are not part of the regular questionnaire. Since this paper aims to analyse the dependencies between the commuting behaviour of employees and their sociodemographic characteristics, several groups of the German population are excluded from the investigation. On the occasion of a mobility survey, Nobis et al. (2019) compared several trends in Germany concerning mobility issues and depicted several changes over this period. First, the German population grew older on average, the trend was primarily driven by the babyboomer generation. The share of household with an age of 65 and above increased from 20 to 30\%. Both the employment rate and the person kilometre travelled for commuting increased by about $10 \%$.

First, only those participants are taken into account, whose primary income is usually based on their efforts. Further on, only the population of working age is considered, which excludes children under the age of 15 (OECD 2020) as well as pensioners. Soldiers, volunteers and farmers are excluded as well as they tend to bias either the regular commuting patterns or the sociodemographic characteristics or both.

Since previous research unveiled differing effects for male and female workers, the variables are analysed separately for the two genders. In the German Microcensus of 2012 gender is coded as a binary variable that distinct men and women. More recent surveys also 
contain an attribute for undefined gender. On this basis, the analysis is limited to conventional gender concepts.

One way to assess a professional's qualification level is to distinct occupational groups. Similar to Alexander and Dijst (2012), this contribution focuses on higher-level professional workers. In accordance to the International Standard Classification of Occupation (ISCO-08), those are defined as legislators, senior officials and managers (ISCO 1), professionals (ISCO 2) and technicians and associate professionals (ISCO 3). They differentiate from semi-skilled white-collar occupations, semi-skilled blue-collar occupations and elementary occupations (International Labour Office (ILO) 2012).

The respondents' levels of education are considered due to the International Standard Classification of Education (ISCED-97). The classes ISCED 5 A (at least a 3-year theorybased program), ISCED $5 \mathrm{~B}$ (qualification for direct labour market entry) and ISCED 6 (advanced research programs) represent the tertiary levels of education (OECD 1999).

To cover both occupational and educational qualification, only respondents with the described ISCED- and ISCO-classifications are considered for the professional's subsample.

Several questions of the German Microcensus survey are open and can be answered voluntarily. The participants with missing values in the analysed variables have been omitted in the analysis.

\section{Descriptive analysis}

Table 1 presents basic descriptive results on the variables selected above. It is distinguished between all respondents and the subset of professionals to allow for some general comparisons. The state of research indicates various effects for men and women. Thus the results for male and female respondents are presented separately.

As the first group of variables, the different commuting distances are tested. The microcensus questionnaire provides 5 distance categories ranging from 0 to $50 \mathrm{~km}$ and more. Respondents with constantly changing workplaces are excluded from the analysis. The results presented in Table 1 are generally in line with the expectations derived from the literature above. Professionals commute longer distances than workers of the full sample and the shares of men that commute longer distances are larger than for women in both cases.

The second group consists of variables related to the respondents' occupation. In the survey, income is measured in 24 nonlinear categories with an increasing range from $0 €$ to $18,000 €$ and more. To create comparable groups, approximate income quintiles are computed on the base of the full sample after data cleaning. As can be seen in Table 1, most of the five income quintiles for men and women are close to a share of $20 \%$. As expected, in both sets the lower-income groups are dominated by women whereas men achieve comparable higher incomes. This observation holds for the group of professionals, although the women's shares are more evenly distributed. More then half of the male professionals are ranked in the highest income quintile.

Besides the income, previous research identified fixed-term contracts, part-time work and supervisory or management-related tasks as possible drivers or restrictions of an employee's commuting behaviour. As implied by the state of research, almost all male respondents worked full-time, while a large share of women of $40 \%$ worked part-time. Unlike before, the shares of part- and full-time workers do not increase or decrease significantly for the professional's data, implying that the average weekly working hours are not a matter of qualification. For fixed-term contracts, striking differences can be found neither 


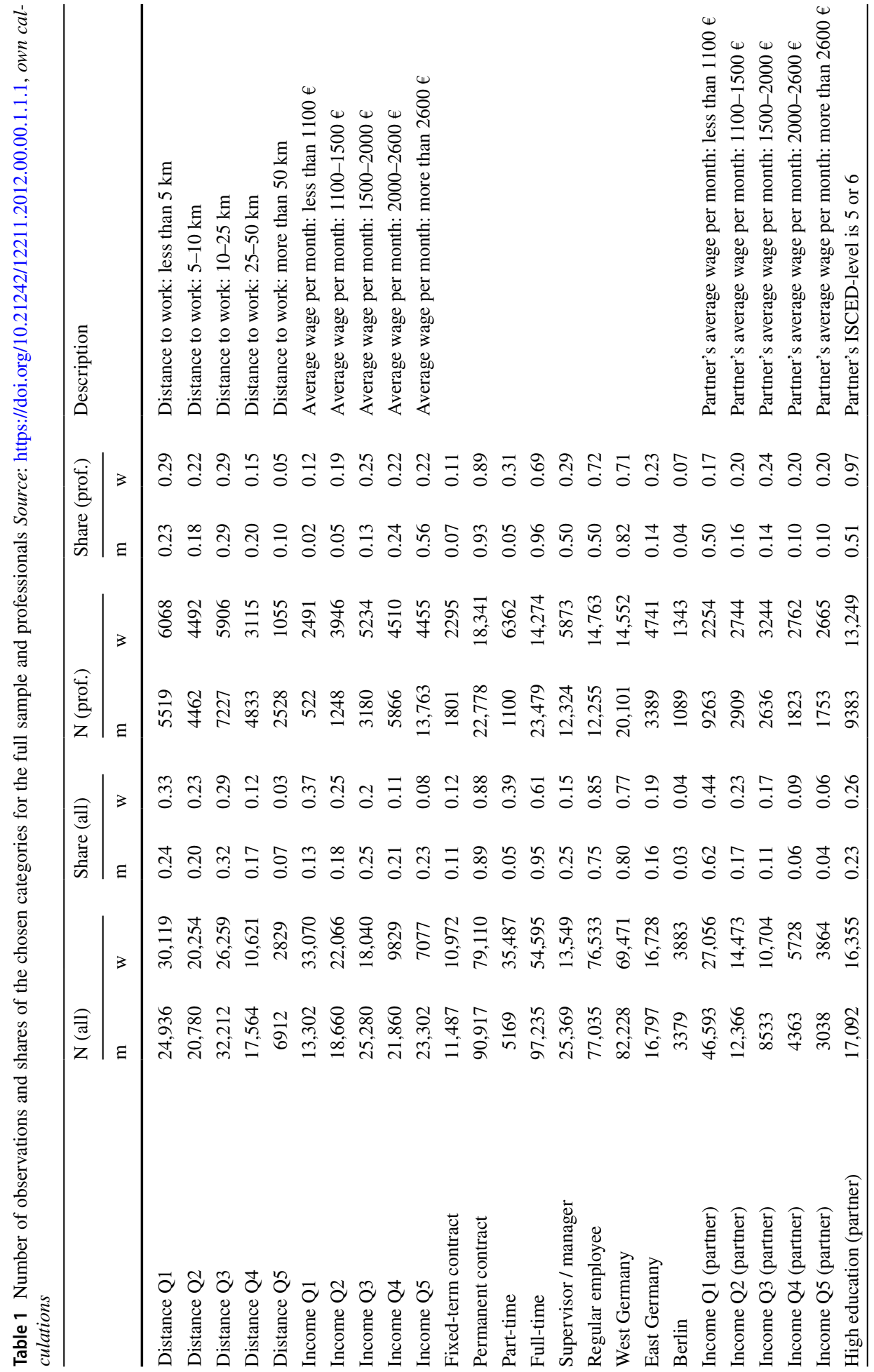




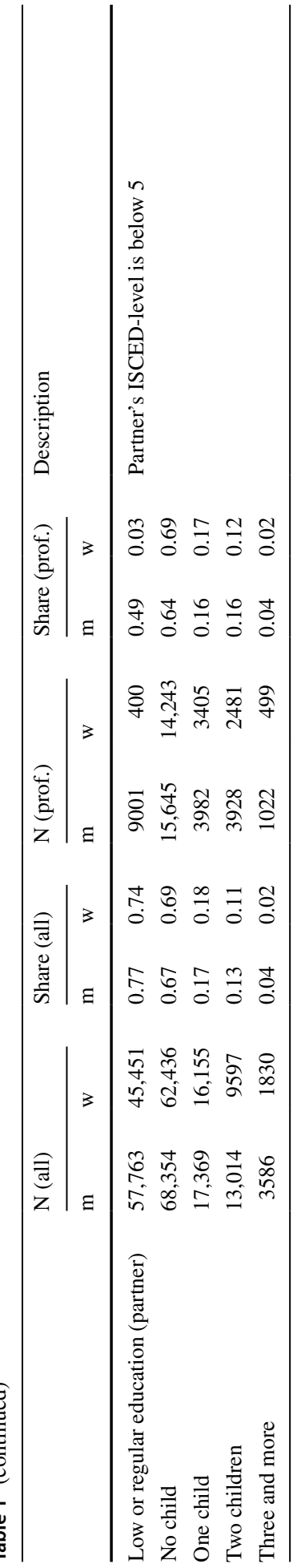


for gender nor for qualification differences. Roughly $90 \%$ of all men and women work in permanent contracts.

As a third group of variables, the federal state of residence is analysed to account for regional differences. In this case, Germany is divided into East and West, while Berlin as a metropolis is considered separately since its economic structure differs from the surrounding rural areas (Haas and Hamann 2008; Haas 2012; Granato et al. 2009). In both groups, approximately $80 \%$ of the respondents stated to live in West Germany, whereas about $20 \%$ are from East Germany and about $4 \%$ reside Berlin, which in general fits official demographic data. However, the distribution of female professional respondents deviate from the official data and is slightly but disproportionately high for Berlin and East Germany. The available data do not allow spatial analyses on a small scale. Thus, only the effects of macroeconomic regions are taken into account.

The last group accounts for the household structure and analyses the dependence of commuting and the spouse's characteristics. Respondents without a partner are not considered in the partner-related analysis. Initially, the partner's income group is measured in the income quintiles as used above. In the full sample $62 \%$ of men's spouses received an average wage of $1100 €$ per month and about $80 \%$ of the partners belonged to the lowest two income groups. Although the women's values are more evenly distributed, but point in the same direction. This decreasing share within the income groups is partly due to the lower availability of high-income potential partners as depicted in the results for the second variable group. However, the result also supports the former observations and theories of previous research on gender-specific differences in socioeconomic factors such as part-time work or role models. These dynamics appear to hold for the group of professional men, although their spouses tend to receive a higher wage, as the lower-income groups are not as strong as those in the complete sample. The values of female professionals are distributed approximately even so that women with higher skills and education form the group with the (on average) best-earning partners.

Since the underpinning data are of 1 year, the effects of long-term developments such as the ageing of children or employees or other life-cycle events are not considered here.

To measure the partner's qualification level, the microcensus data provide the ISCEDclassification as used above. As for the selection of the professional's subsample, the ISCED 5 and 6 classes are used to separate the respondent's partners with higher education from the full sample. As Table 1 depicts, gender difference on the partner's education is not prevalent for both men and women, as long as the full sample is considered. Approximately one-quarter of the partners are highly qualified due to the ISCED-classification. When switching to the professionals, this parity disappears, as almost all (97\%) of the female respondents stated to have a partner with higher education, whereas the male respondents declare only about $50 \%$ of their partners as highly educated. This tendency of professional women to couple with higher-skilled partners goes along with the general observations on the partners' income.

Finally, the number of children per family is measured in four categories ranging from 0 to 3 or more children. As expected, men and women have approximately the same number of children. Also, there are no significant differences between the educational groups.

\section{Ordered logit regression}

To estimate the influence of the variables introduced in Table 1 on the commuting distance, four ordered logistic regression models are calculated. Their results are presented in 


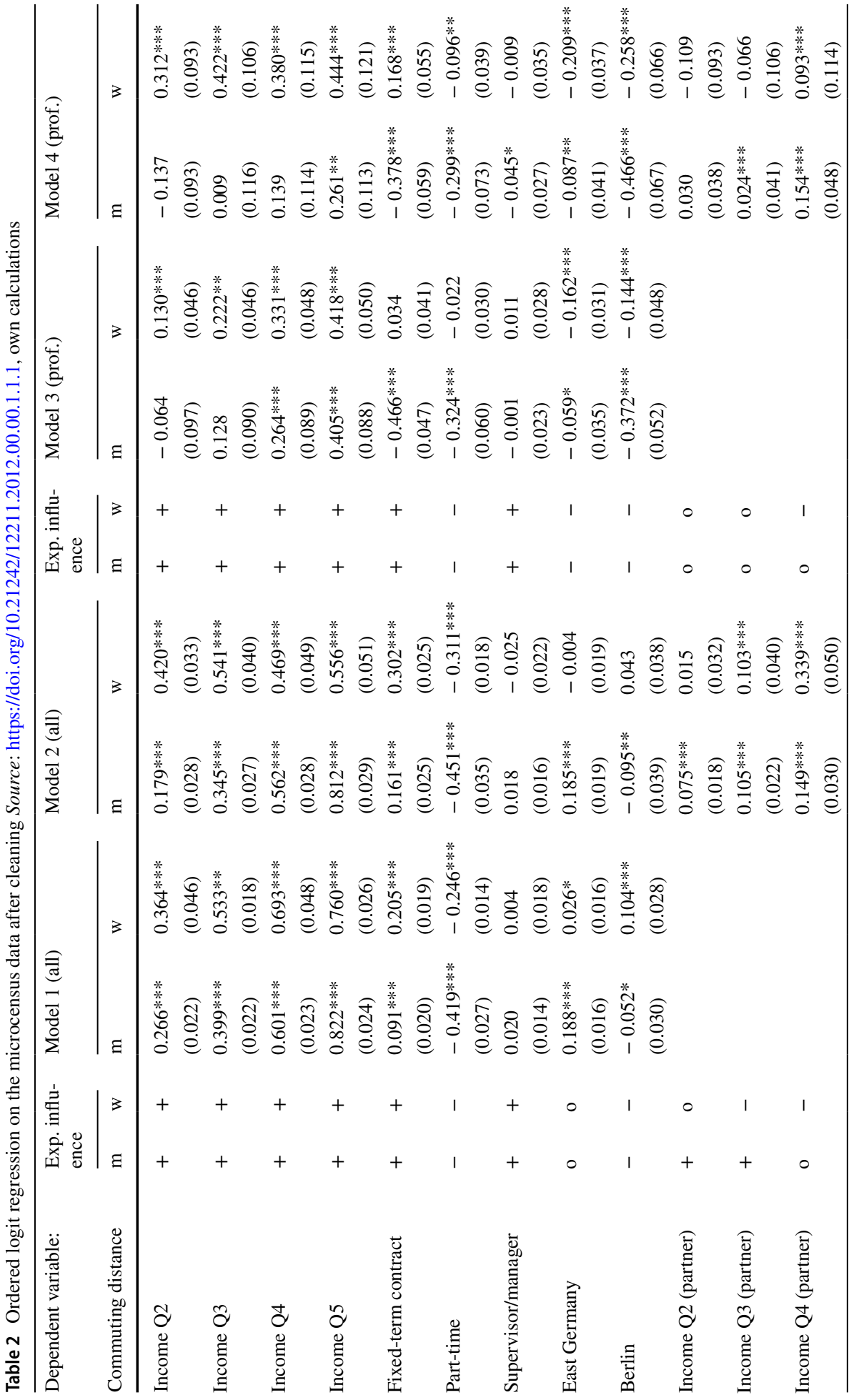




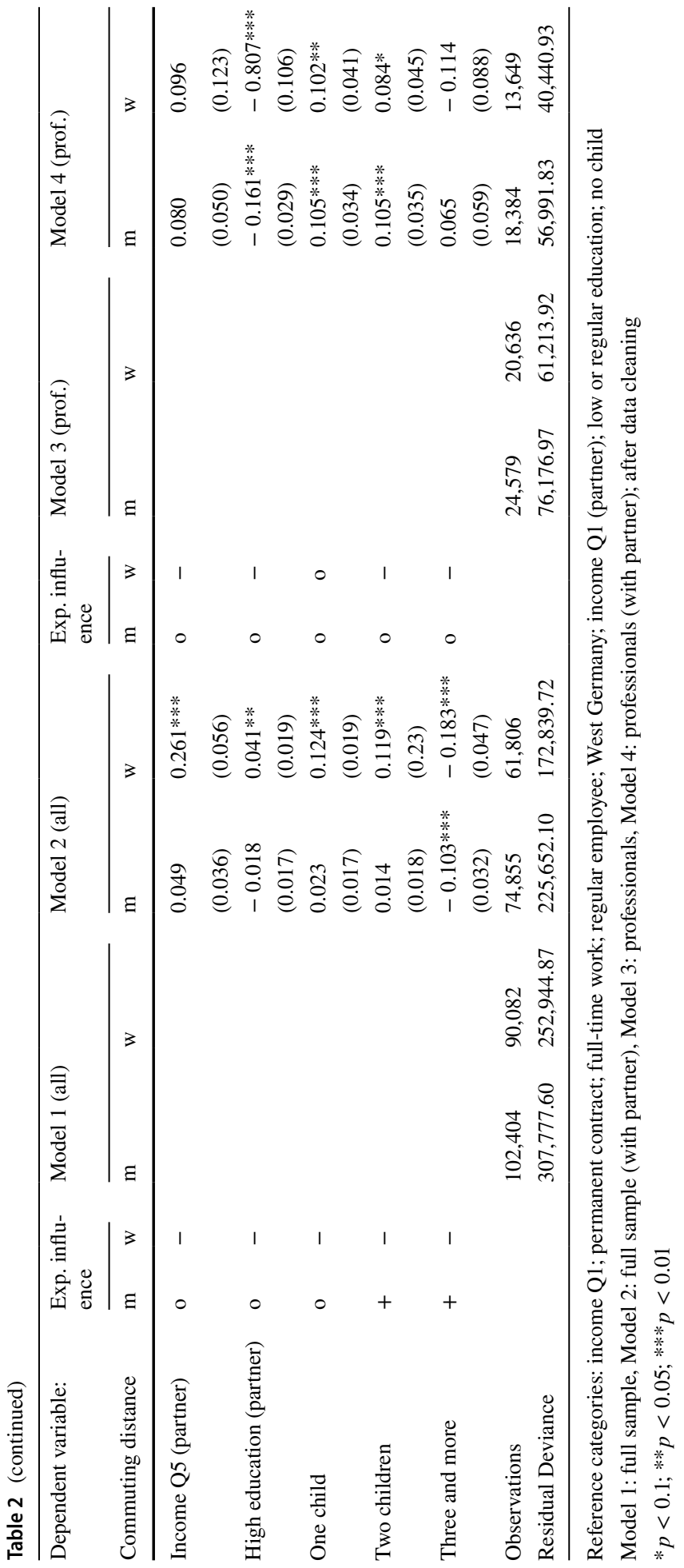


Table 2 and show the expected influence of the variables in comparison to a suitable reference category and are derived from the literature review above.

Logistic regression approaches are suitable to estimate models for ordinal variables. Since the German Microcensus provides categorical information on a respondent's commuting distance $d, Y_{i}$ ranges from 0 to $50+\mathrm{km}$. Following the work of Fahrmeir et al. (2013) and Agresti (2010), an ordered logistic regression approach is applied to the data to estimate the effects of the sociodemographic variables on the commuting distances.

$$
Y_{i}=r=\left\{\begin{array}{l}
1, \text { if } 0 \mathrm{~km} \leq d_{i}<5 \mathrm{~km} \\
2, \text { if } 5 \mathrm{~km} \leq d_{i}<10 \mathrm{~km} \\
3, \text { if } 10 \mathrm{~km} \leq d_{i}<25 \mathrm{~km} \\
4, \text { if } 25 \mathrm{~km} \leq d_{i}<50 \mathrm{~km} \\
5, \text { if } 50 \mathrm{~km} \leq d_{i}<\infty,
\end{array}\right.
$$

where $r \in\{1, \ldots, 5\}$ denotes the category of distance to work for respondent $i$. The probability that a respondent is in a certain category or lower can be written as

$$
P\left(Y_{i} \leq r\right)=F\left(\lambda_{r}+\boldsymbol{x}_{i}^{\prime} \boldsymbol{\beta}\right)
$$

with $\mathrm{F}$ being a logistic cumulative distribution function of $\lambda_{r} \in\{0 \mathrm{~km}, 50 \mathrm{~km}\}$ as the corresponding categories' threshold and $\boldsymbol{x}_{\boldsymbol{i}}^{\prime} \boldsymbol{\beta}$ as the product of covariates and a parameter vector without an intercept. A regression on this probability uses $\lambda_{r}$ and $\boldsymbol{\beta}$ as parameters and $\boldsymbol{x}_{\boldsymbol{i}}$ as regressors.

When applying a logit transformation to Eq. 1, the cumulative logits can be written as

$$
\begin{aligned}
\operatorname{logit}\left[P\left(Y_{i} \leq r\right)\right] & =\log \frac{P(Y \leq r)}{1-P(Y \leq r)} \\
& =\log \frac{P\left(Y_{i} \leq r\right)}{P\left(Y_{i}>r\right)} \\
& =\lambda_{r}+\boldsymbol{x}_{i}^{\prime} \boldsymbol{\beta} .
\end{aligned}
$$

The log odds defined by Eq. 2 are computed in R (R Core Team 2019) with the polr-function of the package MASS (Venables and Ripley 2002). Unlike in Fahrmeir et al. (2013) and Agresti (2010), polr defines log odds as

$$
\operatorname{logit}[P(Y \leq r)]=\lambda_{r}-\boldsymbol{x}^{\prime} \boldsymbol{\beta}
$$

for better interpretation. By that, every result depicted in Table 2 can be interpreted as the logarithmic odds for being in a higher commuting category. Since for each log odds $r$, $\log (r)<1$ for $r<0$ and $\log (r)>1$ for $r>0$, the direction of the estimated influence can be assessed without further transforming.

For each of the estimated models, the log odds and standard errors are presented for different samples. The first model contains all male and female respondents of the German Microcensus after data cleaning, whereas the second model is limited to respondents living in a partnership to control for household effects.

The third and fourth model are set up alike but are based on the subsample of professional respondents due to the ISCED and ISCO classifications as introduced above. Thus, 
the number of observations in the different samples ranges from about 100,000 in the male column of model 1 down to 14,000 in the female column of model 4 .

\section{Occupational implications}

As shown in the state of research section, income has already been identified as one of the most important influences on an individual's commuting behaviour by previous research. As Table 2 implies, being in a higher income group is in general significantly and positively related to a person's commuting distances and holds for all samples with only a few exceptions. For both columns of model 1, the coefficients for the income increase steadily with a rising wage, and are all positive and highly significant. The effects tend to be relatively higher for female employees, except in the highest category. For men in the highest income group, the odds for being in a higher commuting class than the reference group are $e^{0.822}=2.28$.

When considering the family constraints as depicted in model 2, most income-related coefficients decrease. Men of medium and high-income groups appear not to be affected distinctively, whereas most coefficients for high-income females lose impact (although not their significance). Oppositely, the coefficients for medium or lower female income slightly increase in comparison to the full sample.

For the professionals, the effects of an increasing income appear not to be as distinct as for the entirety of respondents. In model 3 and 4, the differences in the commuting distances between the reference group and male professionals with a medium or lower income lose their significance and are less distinct or (although insignificant) even negative. Adding the set of family constraints leads to an even more declining relation, leaving only the highest income group with a significant difference to the reference group. In comparison to their male counterparts, the income effect is less diverging for female professionals of model 3, although the coefficients are comparably smaller than in the sub-sample. Unlike in the full sample and for male respondents, adding family constraints results in higher distances in every class. Especially the low and medium-income classes are affected, with coefficients rising from 0.130 to 0.312 and 0.222 to 0.422 respectively. However, since some groups contain only comparably few respondents (Table 1), the results might be biased. Moreover, multicollinearity with variables such as part-time work might be an issue.

Next to income, the temporal limitation of employment contracts has been assumed to exert an influence on an individual's commuting distance. As Table 1 depicts, only around $10 \%$ of every group hold fixed-term contracts whereas about $90 \%$ of all respondents (after cleaning) are permanently employed.

Turning to the full-sample models of Table 2, the assumption of a positive relationship between a fixed-term contract and the commuting distance can be confirmed, with more distinct effects for women than for men. The results are in line with the expectations derived from the literature and all coefficients are significant on a 99\% level. Model 3 demonstrates that a fixed-term employed male professional's odds for being in a lower commuting distance category than his counterpart with a permanent contract are $1-e^{0.466}=0.37$, thus $37 \%$ higher. The female coefficient is close to zero and not significant on a sufficient level.

Under family constrains (model 4), the coefficients for female professionals gain in both significance and relevance. When being part of a household, a fixed-term working female professional's odds to commute a longer distance than her permanently employed 
counterpart, are $e^{0.168}=1.18$, thus $18 \%$. Under family constraints, the male coefficient remains distinctively negative.

In contrast to fixed-term contracts, part-time work is assumed to exert an overall negative influence on the commuting distances. While fixed-term contracts are associated with a full salary, part-time workers usually receive a reduced wage that makes commuting comparably more expensive and stressful.

The results of Table 2 are in line with these expectations. The coefficients are negative for all sub-samples and thus indicate a negative influence of part-time work on the commuting distance. As a tendency, the effects are comparably less striking for the professionals. Especially for female professionals, the influence dilutes in both power and significance.

In general, the estimated impacts of the occupational variables on the odds for commuting longer distances are in line with the expectations and fit several assumptions. First, assumption A 1.1 stated a correlation between higher incomes and longer commuting distances and can be confirmed at this point. The results of model 1 and 2 are in line with the expectations derived from the literature and assuming a positive correlation of income and commuting distance with stronger results for men and women. Adding family constraints results in shorter commuting distances also for men but especially for women with higher income, which is in line with traditional role models of "male breadwinners" and "female housewives" (Scheiner and Holz-Rau 2017; Augustijn 2018; Surprenant-Legault et al. 2013; Sultana 2005). Concerning previous research, the effects for male and female workers are considered separately. As described, assumption A 1.1 is valid for female professionals in the full sample. It must be limited only slightly when adding family constraints, as the corresponding coefficients do not increase linearly. For male professionals, assumption A 1.1 can neither be accepted nor rejected explicitly. On the one hand, the coefficients at least for medium or higher income groups rise steadily. On the other hand, most results are not significant on a sufficient level, particularly in comparison to the full sample and the female counterparts. Compared with the full workforce, the effects of income changes dilute for professionals.

Assumption A 1.2 stated that professionals with fixed-term contracts commute longer distances than those with permanent contracts. Both rather lower costs for commuting than for relocation and a higher acceptance for commuting stress due to the temporal limitation were suggested to form the underpinning mechanism of a higher willingness to commute. As the results show, the assumption can be accepted for the full-sampled models and rejected for male professionals. The case of female professionals appears to be more complex, as at least under family constraints a positive and significant influence is found. However, all coefficients of model 2 and 4 are higher than their counterparts. As higher (opportunity) costs of relocation can be assumed for households than for singles, this observation gives support to the view on commuting as an avoidance-behaviour for relocation (Pfaff 2012; Rüger and Sulak 2017; Scheiner 2016). Nevertheless, the negative coefficients for male professionals remain surprising, since a positive influence was expected. One corresponding observation based on the descriptive results (Table 1) is that a large share of male professionals receives comparably high incomes that come along with longer commuting distances. Additionally, male professionals represent the subsample with the lowest share of fixed-term contracts. Since both the literature and descriptive statistics suggest an aversion to this kind of employment, there is a row of viable explanations. First, male workers could show a low willingness to commute and thus accept fixed-term contracts close to their place of residence. Second, these workers might show an extraordinary high 
willingness to relocate their residence for a comparably short period to shorten the daily commuting distance. The less negative (but still distinct) coefficient for male partners living in a household give support to this approach since the relocation of a household can be assumed to be more costly and difficult due to bargaining, more restrictions and higher (opportunity) costs (Pfaff 2012; Wagner and Mulder 2015; Van Ommeren et al. 1999). Third, Table 1 suggests gender-related differences in the reasons for seeking (or finding) no permanent employment with an influence on commuting behaviour.

Assumption A 1.3 can be accepted in all models. The influence of part-time work on the commuting distance is negative in all samples, although the effects for female professionals are not significant until family constraints are added. In general, the estimates for the professional's sub-samples are closer to zero. This result might be channelled by a higher income of better-educated employees. As Table 1 depicts, the incomes of both male and female professionals are higher than in the full sample, whereby men benefit most from higher education. Since commuting costs can be assumed to be equal for every employee, professionals have to spend a lower share of their income to cover a similar distance.

As the corresponding row depicts, assumption A 1.4 must be rejected for all models since all coefficients are positive but close to zero and without significance. As an exception and contrary to McQuaid and Chen (2012), male professionals in managerial occupations are found to have a slightly higher chance to commute a shorter distance than other professionals. The finding gives support to Sultana (2005), who unexpectedly found managers in the Atlanta metropolitan area to commute comparably short distances.

\section{Regional divergence}

The second set of assumptions refers to the impact of regions within Germany as the state of research suggests differences in the commuting behaviour of East and West German professionals.

Indeed, the models 3 and 4 validate that especially for East German female professionals the odds are considerably high to be in a lower commuting class than West German female professionals. In comparison, in the full sample, the estimated coefficients for the females lose their significance and are close to zero, whereas the odds for men to be in a higher commuting class than West Germans are around $20 \%$ in both models. Berlin is separated from the analysis as it is Germany's most populated city and a centre of economic activity. Hence it is likely that the city's worker exerts a different commuting behaviour than their counterparts in the surrounding federal states of East Germany. Indeed, this presumption holds at least for professionals and men from the full-sample, who are more likely to commute shorter distances whereas the effect for women is the opposite.

In general, assumption A 2.1 is valid and especially matches the results for female professionals. However, the results must be interpreted with caution since there is a row of possible biases. First, living and working in a certain region could be correlated with variables of the occupational set, since economic differences between East and West Germany and Berlin are prevalent and known (Bogai et al. 2014; Haas and Hamann 2008; Granato et al. 2009). Moreover, these differences could also account for the quality of infrastructure or the balance of rural and urban areas, which previous research suggests to be important drivers of commuting (Kohl 2014; Haas and Hamann 2008). The finding, that commuting connects rural areas, suburbs and the urban core of a region, as well as economic strong and weak areas, is in line with the literature (Einig and Pütz 2007; Winkelmann 2010). The underpinning economic dynamics point in the same direction as the findings from other 
research areas e.g. in North America (Shearmur and Motte 2009; Sultana 2002), although most of the geographic models applied in the literature are of smaller scale and thus of these spatial characteristics.

\section{Household dynamics}

Turning to the household characteristics, a respondent's partner's income is considered to influence the respondent's commuting distance as it is part of the households joint optimisation problem. As shown above, previous research suggests the traditional "male breadwinner" and "female housewife" model as the major explanation for gender differences in commuting times. Thus, the direction of the influence is expected to differ between male and female respondents.

For the full sample, model 2 estimates an overall positive influence of the partner's income on an individuals commuting distance. For male respondents, a partner's income within the quintiles 3 and 4 exerts the strongest influence on the men's' commuting distance with the odds for being in a higher commuting category being $11 \%$ to $16 \%$. In comparison, women's commuting distances are most stimulated by a partners income within the quintiles 4 and 5, with the odds being $30 \%$ resp. $40 \%$.

Assumption A 3.2 states a negative influence of the partner's education on an individuals commuting distance with males being less affected than females.

Again, the estimated coefficients differ by both gender and educational status of the respondent. In the full sample, only the female's odds for commuting longer distances are significant, although with odds of only $e^{0.041}=1.04$, thus $4 \%$. However, the men's commuting distance is not stimulated significantly by the spouses' educational level.

In comparison, a significant and strong influence of the partner's education on the own commuting distance is observed for the professionals. As expected, the effect is much stronger for females with the odds being $1-e^{-0.807}=0.55$, thus $55 \%$ to be in a lower commuting class than a counterpart with a less educated partner.

Finally, the influence of children on the commuting distance is tested. As discussed above, children, on the one hand, add further restrictions to the households joint optimisation problem, that can be assumed to cause longer commuting distances or labour division within the household. Moreover, additional household members also increase the costs of relocation. On the other hand, previous research suggests a negative impact of children on the commuting distance at least for women. Usually, these observations are explained with labour division based on role models and a higher demand for family-time (Ruppenthal and Lück 1999).

The estimated coefficients are not in line with the expectations. In the full sample, the odds of women with one or two children to commute longer distances than women without children are about $13 \%$. Only women with three or more children are likely to commute shorter distances. For men, the coefficients for one and two children are not significant and close to zero, while the effect of having three and more children is similar to their female counterparts. In comparison to the full-sample model, the effect of children on the commuting distance dilutes for female professionals, since both significance and coefficients decline. In contrast, the odds of male professionals with one or to children to commute longer distances are comparably higher and significant on a $99 \%$ level.

In sum, the household variables can be confirmed to influence the respondents commuting distance, although not all results meet the expectations. 
Initially, assumption A 3.1 can neither be accepted nor rejected. On the one hand, especially the estimates for female professionals do not meet the expectations since they do not decrease with an increasing income of the partner. However, the overall influence of the partner's income dilutes when turning from the full sample to the professional's subset.

In general, the effect is visible for male and female as well as professional and other employees but reveals some interesting differences. Especially the results for female respondents are surprising at this point, as a negative influence of a woman's partner's income on her commuting distance was expected. The data cannot confirm the observations of e.g. Ruppenthal and Lück (1999), Scheiner (2016) or Hjorthol and Vågane (2014) regarding the expected influences of traditional role models and the corresponding division of tasks between spouses. For both male and female professionals, the coefficients are closer to zero and lose significance compared to the full-sample estimates. This distinction suggests a decreasing impact of the partner's income on a respondent's commuting distance with an increasing educational level of the respondent. Obviously, other characteristics gain in importance.

Sultana (2005) described fundamental differences between the commuting patterns in American (dual-earner households commutes are slightly longer than single-earner commutes) and European (no significant differences or mixed effects) cities and refers on contributions around the year 2000. Sultana (2005) themselves concluded for the metropolitan area of Atlanta, that the commute times of dual-earner households are comparably shorter. For Germany, an employee's commuting distance is likely to increase, once the spouse is not in the lowest income category (or in the case of female professionals, not below $2000 €$ per month), which gives support to the theory of more complex location choices and thus longer commutes of dual-earner households. Considering the previous findings and the results of this contribution, these differences might be ripe for a more detailed re-examination. However, they are not necessarily outdated, as different study-designs could be a bias.

Nevertheless, these findings might be limited due to two constraints. Note that a considerable share of men's partners (usually women) are in the lowest income class, regardless of the men's own educational and occupational status (Table 1). The partners of female professionals (usually men) are roughly equally distributed along with the income groups, whereas about $67 \%$ of their counterpart in the full-sample are in income quintile 1 or 2. Moreover, a correlation of the income variable with both other variables such as education and the partner selection is possible and could bias the result at this point.

The educational status of the partner was found to decrease the commuting distance of professionals. Especially female professionals were found to commute shorter distance when their partner is well-educated. Although this finding is generally in line with the literature (Scheiner 2016), the results are much higher than for any other group. Previous research suggests variables such as a valuation of family-time to reduce commuting distances within households (Swärdh and Algers 2016; Vuk et al. 2016). Moreover, a general affinity for short commutes due to costs and negative health effects is apparent. To explain the striking coefficient of female professionals, traditional role-models fits well to the observed differences within the group of professionals. Traditional labour division within the household could explain both a comparably low income and a high share of part-time work for female professionals (Table 1). One viable interpretation for the small or slightly negative coefficients of the respondents in the full-sample builds on economic restrictions. In the models 3 and 4 both or at least one partner is a professional, while in the models 1 and 2 no or maximal one partner belongs to the highly skilled and educated group of workers. Thus, as the expected household income within the full-samples is lower, a longer commuting distance of both partners might be necessary to maintain a sufficient 
level of the households cumulative income. Nevertheless, this interpretation is not sufficiently backed by the corresponding coefficients, that tend to increase with a higher partners' income. Again, a correlation of the income variable with the educational level or partner selection patterns is possible and could bias the estimates.

However, since couples with two highly qualified spouses have high odds to commute shorter distances than the reference group or the respondents of the full sample and the effects are less distinct for men, assumption A 3.2 is validated.

Finally, coefficients for the number of children were estimated and found to influence the commuting distance for certain sub-samples. Based on the state of research, contrary effects on the gender groups were presumed, with men commuting longer and women shorter distances with every additional child (McQuaid and Chen 2012; Motte-Baumvol et al. 2017; Hjorthol and Vågane 2014). To assess the differences between the entirety of workers and the professional's subsample, assumption A 3.3 states less significant impacts of children on the commuting distances.

Focusing on the respondents of the full-sample models, the positive odds for longer commutes of women with children than for women without children are surprising since they differ from most of the previous findings and suggestions (McQuaid and Chen 2012; Hjorthol and Vågane 2014; Sultana 2005). Only that finding, that women with three and more children (and thus numerous additional restrictions) travel shorter distances, is in line with the expectations. The results for males do generally not contradict the expectations, but the coefficients are less positive than suggested by the literature. Apparently, longer commutes are accepted by parents, as long as the additional burden caused by childcare is not too high.

An economic explanation arises from the higher relocation cost of a household with additional members as described above. Since the needs of a child, such as a suitable kindergarten, school or neighbourhood, have to be considered in the decision for a residential location, the commuting distances increase, whereas the demand for family-time increases at the same time. A well-known reaction to this more complicated problem is that one partner accepts a new (possibly part-time) job in the vicinity with both a probably worse qualification-match and a lower income, whereas the partner with a higher willingness to commute keeps working full-time in a longer distance. Both empirical findings on this willingness to commute and traditional role models suggest that usually, women tend to reduce their commuting distance in this kind of situation (Hjorthol and Vågane 2014; McQuaid and Chen 2012; Auspurg and Schönholzer 2013; Sultana 2005; Motte-Baumvol et al. 2017). The respondents of the professional's sub-sample fit better to these previous findings since for highly educated fathers positive and for highly educated mothers negative or at least comparably smaller coefficients were estimated.

Nevertheless, from the first child on, there is a decline of the men's and women's coefficients with any additional child, with the male's being usually larger than the female's. Thus, the observed impacts fit the assumption A 3.3 sufficiently. The increasing commuting distances of men are in line with the literature as presented above. Thus, assumption A 3.3 can be accepted, but the results dilute in comparison to previous investigations. Further on, the results for the influence of three children have to be treated with caution, since the underpinning group of respondents is comparable small and accounts for only $2 \%$ of the sample size. 


\section{Conclusion}

This analysis aims to complement the broad state of research on commuting with the perspective of professional workers. Contributions such as Wrede (2013), Hjorthol and Vågane (2014), Sultana (2002, 2005) and Groot et al. (2012) considered the occupational or educational status and provide initial suggestions for certain effects for highly educated workers. The preceding analysis extends previous and more general findings on the commuting of German professionals since they are found to commute longer distances than other employees (Nobis and Kuhnimhof 2018; Haas 2012; Pfaff 2012). In both educational groups, men commute longer distances than women. Gender-differences in the other variables such as part-time work or income are in line with the extensive body of international literature as described above.

The main finding on professionals' commuting behaviour is that individual occupational variables are still of importance, but their overall influence dilutes in comparison to other groups. Especially income, which is used by classical economic literature as the major explanation for commuting decisions, reveals a comparatively small effect on professionals' commuting distances.

Instead, the shifts in the household-coefficients indicate a higher preference for family time instead of commuting time in relative terms. As suggested by previous research (e.g. Swärdh and Algers 2016; Vuk et al. 2016; Hjorthol and Vågane 2014; Scheiner and HolzRau 2017; Sultana 2005 or Groot et al. 2012), the impact of the partners' characteristics on the commuting distance is determined by gender differences. Within a household, a shift in a woman's educational and occupational status makes her commuting behaviour less dependent on her children but rather dependent on her husband's economic success. The difference of male professionals to their counterparts with lower education remains ambiguous. Nevertheless, with increasing occupational and educational status, fathers commute longer distances.

However, the results have to be treated with appropriate caution due to some limitations of the applied methods. First, the "traditional" variables show an overall trend towards less explanatory power for the variation in the professional's commuting distances. Thus, a general bias of the estimated coefficients due to an omitted variable with explanatory content is conceivable. Second, several coefficients of the models may be somehow biased by multicollinearity. For example, several variables such as education, fixed-term contracts or part-time work and gender are likely to be correlated with at least the income variable. Table 1 and the regression results give support to this apprehension. Moreover, the characteristics are not distributed evenly along the categories and several very small groups (such as male professionals with a very low income) potentially bias the estimates. Finally, according to Fahrmeir et al. (2013), the covariates of an ordered logit regression model must not be dependent on the response variable. Although the phenomenon of commuting can mostly be treated as a reaction to the variables analysed above, interdependencies and reversed causality e.g. in the case of income and the commuting distance cannot be ruled out entirely.

Due to limitations in the available data and regulations on privacy and data protection, two promising approaches, in particular, were not carried out. First, the integration of smaller scaled geographical data in the present framework yields great potential for improving model quality. Contributions such as Horner et al. (2015), Schleith et al. (2016), Sultana (2005) or Korsu and Le Néchet (2017) used such data to determine the influence of small-scale conditions on commuting behaviours and rely on quantitative spatial concepts 
such as excess commuting. Groot et al. (2012), Hjorthol and Vågane (2014), Weber and Sultana (2008), Shearmur and Motte (2009) or Wrede (2013) stated a spatial sorting of workers by their qualification, due to the economic or social attributes of a region, city or neighbourhood. Better-educated workers are usually found to commute towards and live in high-income areas with a high population density in almost every analysed country or region.

The comparison of eastern and western federal states in Germany allows checking for the overall influences of e.g. economic activity and infrastructure on a macro-scale. Separating Berlin from the analysis gives only a very rough idea of disparities of urban and rural environments and their impact on residence- and workplace-choice and commuting. By refining the present approach, further research should analyse residence-, workplaceand mode-choices in order to untangle the interdependences between various social, professional and economic groups.

Such approaches already turned out to be useful in explaining general occupational mobility and are likely to extend the explanatory power of the findings beyond the sociodemographics also for professionals (Wrede 2013; Scheiner 2016; Zarabi et al. 2019; Groot et al. 2012). Especially for case studies on the commuting of employees within a certain region, city or metropolis, specific knowledge of the underpinning geography is indispensable (Sultana 2005; Surprenant-Legault et al. 2013; Shearmur and Motte 2009; Scheiner 2016; Schleith et al. 2019).

Second, a time series analysis of the microcensus data over several years could grant insights into the long run developments of mobility and changes in the explanatory sociodemographic variables on an individual and aggregated level. Such approaches provide a sound foundation for long term policy decisions on necessary services and infrastructure. Moreover, a consideration of the different stages in individuals' life cycles, as applied in Beige and Axhausen (2012) or Zarabi et al. (2019), might address deeper and more fundamental connections between socioeconomic characteristics and the corresponding commuting distances, since these variables are likely to change over time.

The results of this analysis provide both the basis for further research regarding the deep determinants of professionals' commuting behaviour and support for a row of policy decisions. Many regions not only in Germany or Europe suffer from a brain-drain and a general competition for skilled labour and economic prosperity with their neighbours. A deep understanding of the determinants of occupational mobility is necessary to efficiently address the causes of professionals' spatial movements. Since professionals are known to differ in their mode choice from other workers (Groot et al. 2012; Habib 2014), the development of appropriate modern mobility concepts that target the professional's needs and favours could prove a beneficial mean for both, regional development and green transportation.

Acknowledgements Open access funding provided by Projekt DEAL.

Author Contributions MK: Data curation, methodology, formal analysis, investigation, software, validation, writing-original draft. EM: Conceptualization, data curation, project administration, resources, methodology, supervision, investigation, writing-review and editing. JL: Resources, supervision, methodology, funding, writing - review and editing. JS: Conceptualization, data curation, funding acquisition, methodology, resources, supervision, validation, writing-review and editing.

\section{Compliance with ethical standards}

Conflict of interest The authors declare that they have no conflict of interest. 
Open Access This article is licensed under a Creative Commons Attribution 4.0 International License, which permits use, sharing, adaptation, distribution and reproduction in any medium or format, as long as you give appropriate credit to the original author(s) and the source, provide a link to the Creative Commons licence, and indicate if changes were made. The images or other third party material in this article are included in the article's Creative Commons licence, unless indicated otherwise in a credit line to the material. If material is not included in the article's Creative Commons licence and your intended use is not permitted by statutory regulation or exceeds the permitted use, you will need to obtain permission directly from the copyright holder. To view a copy of this licence, visit http://creativecommons.org/licenses/by/4.0/.

\section{References}

Agresti, A.: Analysis of Ordinal Categorical Data. Wiley Series in Probability and Statistics, 2nd edn. Wiley, Hoboken (2010). https://doi.org/10.1002/9780470594001

Aguilera, A.: Growth in commuting distances in French polycentric metropolitan areas: Paris, Lyon and Marseille. Urban Stud. 42(9), 1537-1547 (2005). https://doi.org/10.1080/00420980500185389

Alexander, B., Dijst, M.: Professional workers @ work: importance of work activities for electronic and face-to-face communications in the Netherlands. Transportation 39(5), 919-940 (2012). https://doi. org/10.1007/s11116-0129400-2

Augustijn, L.: Berufsbedingte Pendelmobilität, Geschlecht und Stress. In: Duisburger Beiträge zur soziologischen Forschung (2018)

Auspurg, K., Schönholzer, T.: An Heim und Herd gebunden? Zum Einfluss von Pendelstrecken auf geschlechtsspezifische Lohnunterschiede. Zeitschrift für Soziologie 42(3), 138-156 (2013)

Barker, L., Connolly, D.: Long distance commuting in Scotland: Scottish Household Survey/Transport Research Planning Group topic report. Transport research series (Scotland. Social Research). Edinburgh: Scottish Executive Social Research (2006)

Beige, S., Axhausen, K.W.: Interdependencies between turning points in life and long-term mobility decisions. Transportation 39(4), 857-872 (2012). https://doi.org/10.1007/s11116-012-9404-y

Bogai, D., Buch, T., Seibert, H.: Arbeitsmarktchancen von Geringqualifizierten: Kaum eine Region bietet genügend einfache Jobs. In: IAB-Kurzbericht, (11/2014) (2014)

Böhm, M., Franz, P., Matthiesen, S.: Studierende Eltern. Journal für Psychologie 24(1), 125-156 (2016)

Borck, R., Wrede, M.: Subsidies for intracity and intercity commuting. In: CESifo Working Paper, 2321 (2006)

Bosworth, G., Venhorst, V.: Economic linkages between urban and rural regions: what's in it for the rural? Reg. Stud. 52(8), 1075-1085 (2018). https://doi.org/10.1080/00343404.2017.1339868

Brautzsch, H.-U.: Pendlerströme führen zur regionalen Angleichung bei Beschäftigung. Wirtschaft im Wandel 23(4), 69-74 (2017)

Buliung, R.N., Soltys, K., Bui, R., Habel, C., Lanyon, R.: Catching a ride on the information super-highway: toward an understanding of internet-based carpool formation and use. Transportation 37(6), 849-873 (2010). https://doi.org/10.1007/s11116-010-9266-0

Champion, T.: Urban-rural differences in commuting in England: a challenge to the rural sustainability agenda? Plan. Pract. Res. 24(2), 161-183 (2009). https://doi.org/10.1080/02697450902827329

Chatman, D.G., Broaddus, A., Spevack, A.: Are movers irrational? On travel patterns, housing characteristics, social interactions, and happiness before and after a move. Travel Behav. Soc. 16, 262-271 (2019). https://doi.org/10.1016/j.tbs.2018.11.004

Clark, B., Chatterjee, K., Martin, A., Davis, A.: How commuting affects subjective wellbeing. Transportation 2357(4), 100 (2019). https://doi.org/10.1007/s11116-019-09983-9

Dauth, W., Haller, P.: Berufsbedingte Pendeln zwischen Wohn-und Arbeitsort: Klarer Trend zu längeren Pendeldistanzen. In: IAB-Kurzbericht, (10/2018) (2018)

De Vos, J., Schwanen, T., Van Acker, V., Witlox, F.: Travel and subjective well-being: a focus on findings, methods and future research needs. Transp. Rev. 33(4), 421-442 (2013). https://doi. org/10.1080/01441647.2013.815665

De Vos, J., Ettema, D., Witlox, F.: Effects of changing travel patterns on travel satisfaction: a focus on recently relocated residents. Travel Behav. Soc. 16, $42-49$ (2019). https://doi.org/10.1016/j. tbs.2019.04.001

DeLoach, S.B., Tiemann, T.K.: Not driving alone? American commuting in the twenty-first century. Transportation 39(3), 521-537 (2012). https://doi.org/10.1007/s11116-011-9374-5 
Einig, K., Pütz, T.: Regionale Dynamik der Pendlergesellschaft: Entwicklung von Verflechtungsmustern und Pendeldistanzen. Informationen zur Raumentwicklung 3(2), 73-91 (2007)

Epifani, P., Gancia, G.A.: Trade, migration and regional unemployment. Reg. Sci. Urban Econ. 35(6), 625644 (2005). https://doi.org/10.1016/j.regsciurbeco.2004.09.003

Ettema, D., Friman, M., Gärling, T., Olsson, L.E., Fujii, S.: How in-vehicle activities affect work commuters' satisfaction with public transport. J. Transp. Geogr. 24, 215-222 (2012). https://doi.org/10.1016/j. jtrangeo.2012.02.007

Eurostat.: Employment and commuting by NUTS 2 regions (1000). https://appsso.eurostat.ec.europa.eu/nui/ show.do?dataset=lfst_r_lfe2ecomm\&lang=en (2019). Accessed 21 June 2020

Evans, G.W., Wener, R.E.: Rail commuting duration and passenger stress. Health Psychol. 25(3), 408-412 (2006). https://doi.org/10.1037/0278-6133.25.3.408

Ewing, R., Pendall, R., Chen, D.: Measuring sprawl and its transportation impacts. Trans. Res. Rec. 1831(1), 175-183 (2003). https://doi.org/10.3141/1831-20

Fahrmeir, L., Kneib, T., Lang, S., Marx, B.: Regression: Models, Methods and Applications. Springer, Dordrecht (2013). https://doi.org/10.1007/978-3-642-34333-9

Ferguson, E.: The rise and fall of the American carpool: 1970-1990. Transportation 24(4), 349-376 (1997). https://doi.org/10.1023/A:1004928012320

Forschungsdatenzentren der Statistischen Ämter des Bundes und der Länder (a): Metadatenreport. Teil I: Allgemeine und methodische Informationen zum Mikrozensus (EVAS-Nummer: 12211, 12212, 12213). Düsseldorf 2019 (2019)

Forschungsdatenzentren der Statistischen Ämter des Bundes und der Länder (b): Mikrozensus 2012, OnSite, Version 1 (2012). https://doi.org/10.21242/12211.2012.00.00.1.1.1

Fuchs, M., Ludewig, O., Weyh, A.: Arbeitslosigkeit in Ost und West: Unterschiede verschwimmen immer mehr. In: IAB-Forum, 2015(1) (2015)

Gardner, B., Abraham, C.: What drives car use? A grounded theory analysis of commuters' reasons for driving. Transp. Res. Part F: Traffic Psychol. Behav. 10(3), 187-200 (2007). https://doi.org/10.1016/j. trf.2006.09.004

Gottholmseder, G., Nowotny, K., Pruckner, G.J., Theurl, E.: Stress perception and commuting. Health Econ. 18(5), 559-576 (2009). https://doi.org/10.1002/hec.1389

Granato, N., Haas, A., Hamann, S., Niebuhr, A.: Arbeitskraftemobilität in Deutschland - Qualifikationsspezifische Befunde regionaler Wanderungs-und Pendlerströme. Raumforschung und Raumordnung 67(1), 21-33 (2009). https://doi.org/10.1007/BF03183140

Green, A.E.: A question of compromise? Case study evidence on the location and mobility strategies of dual career households. Reg. Stud. 31(7), 641-657 (1997). https://doi.org/10.1080/00343409750130731

Groot, S., Groot, H., Veneri, P.: The educational bias in commuting patterns: micro-evidence for the netherlands. SSRN Electron. J. (2012). https://doi.org/10.2139/ssrn.2119929

Gutierrez, F.: Commuting patterns, the spatial distribution of jobs and the gender pay gap in the U.S. SSRN Electron. J. (2018). https://doi.org/10.2139/ssrn.3290650

Haas, A.: Mobilität zwischen Regionen: Pendlerströme Fließen überwiegend von Ost nach West. In: IABForum (2012/2), pp 68-73 (2012)

Haas, A., Hamann, S.: Pendeln -ein zunehmender Trend, vor allem bei Hochqualifizierten. In: IAB-Kurzbericht, (2008/6) (2008)

Habib, K.N.: Household-level commuting mode choices, car allocation and car ownership level choices of two-worker households: the case of the city of Toronto. Transportation 41(3), 651-672 (2014)

He, S.Y., Hu, L.: Telecommuting, income, and out-of-home activities. Travel Behav. Soc. 2(3), 131-147 (2015). https://doi.org/10.1016/j.tbs.2014.12.003

Hjorthol, R., Vågane, L.: Allocation of tasks, arrangement of working hours and commuting in different Norwegian households. J. Transp. Geogr. 35, 75-83 (2014). https://doi.org/10.1016/j.jtran geo.2014.01.007

Horner, M.W., Mefford, J.N.: Investigating urban spatial mismatch using job-housing indicators to model home-work separation. Environ. Plan. A: Econ. Space 39(6), 1420-1440 (2007). https://doi. org/10.1068/a37443

Horner, M.W., Schleith, D.K., Widener, M.J.: An analysis of the commuting and jobs-housing patterns of older adult workers. Prof. Geogr. 67(4), 575-585 (2015). https://doi.org/10.1080/00330 124.2015.1054018

International Labour Office (ILO): International Standard Classification of Occupations 2008 (ISCO-08): Structure, group definitions and correspondence tables (2012)

Kakihara, M., Sørensen, C.: Practising mobile professional work: tales of locational, operational, and interactional mobility. Info 6(3), 180-187 (2004). https://doi.org/10.1108/14636690410549507 
Kanaroglou, P.S., Higgins, C.D., Chowdhury, T.A.: Excess commuting: a critical review and comparative analysis of concepts, indices, and policy implications. J Transp Geogr 44, 13-23 (2015). https://doi. org/10.1016/j.jtrangeo.2015.02.009

Kim, T.-K., Horner, M.W., Marans, R.W.: Life cycle and environmental factors in selecting residential and job locations. Hous. Stud. 20(3), 457-473 (2005). https://doi.org/10.1080/02673030500062335

Kley, S.: Gefährdet Pendelmobilität die Stabilität von Paarbeziehungen? Einflüsse von Erwerbskonstellationen und Haushaltsarrangements in Ost-und Westdeutschland auf die Trennungswahrscheinlichkeit von Paaren. Zeitschrift für Soziologie 41, 356-374 (2012)

Kohl, H.: Zum Wandel berufsbedingter Mobilität in der Wissensökonomie. Geographische Rundschau 66(12), 26-31 (2014)

Korsu, E., Le Néchet, F.: Would fewer people drive to work in a city without excess commuting? Explorations in the Paris metropolitan area. Transp. Res. Part A: Policy Pract. 95, 259-274 (2017). https:// doi.org/10.1016/j.tra.2016.10.030

Krause, P.: 30 Jahre seit dem Mauerfall: Fortschritte und Defizite bei der Angleichung der Lebensverhältnisse in Ost-und Westdeutschland. DIW-Wochenbericht 86(45), 827 (2019)

Kümmerling, A.: Beschäftigungsentwicklung und Arbeitszeiten von Frauen in Deutschland - eine Erfolgsstory? Zeitschrift für Arbeitswissenschaft 69(1), 23-29 (2015). https://doi.org/10.1007/BF03373933

Layman, C.C., Horner, M.W.: Comparing methods for measuring excess commuting and jobs-housing balance. Transp. Res. Rec. J. Transp. Res. Board 2174(1), 110-117 (2010). https://doi. org/10.3141/2174-15

Manderscheid, K.: Mobile Ungleichheiten. Eine sozial-und infrastrukturelle Differenzierung des Mobilitätstheorems. Österreichische Zeitschrift für Soziologie 41(1), 71-96 (2016). https://doi.org/10.1007/ s11614-016-0192-z

McQuaid, R.W., Chen, T.: Commuting times: the role of gender, children and part-time work. Res. Transp. Econ. 34(1), 66-73 (2012)

Morris, E.A., Zhou, Y.: Are long commutes short on benefits? Commute duration and various manifestations of well-being. Travel Behav. Soc. 11, 101-110 (2018). https://doi.org/10.1016/j.tbs.2018.02.001

Motte-Baumvol, B., Bonin, O., Belton-Chevallier, L.: Who escort children: mum or dad? Exploring gender differences in escorting mobility among parisian dual-earner couples. Transportation 44(1), 139-157 (2017)

Nobis, C., Kuhnimhof, T.: Mobilität in Deutschland - MiD. Ergebnisbericht. BMVI, infas, DLR, IVT. Ed. by 2018 (2018)

Nobis, C., Kuhnimhof, T., Follmer, R., Bäumer, M.: Mobilität in Deutschland -MiD. Zeitreihenbericht 2002 -2008 -2017. Ergebnisbericht. BMVI, infas, DLR, IVT, infas 360 (2019)

OECD: Classifying educational programmes-manual for isced-97 implementation in OECD countries (1999)

OECD: Working age population (2020). https://data.oecd.org/pop/working-agepopulation.htm. Accessed 28 Mar 2020

Oakil, A.T.M., Nijland, L., Dijst, M.: Rush hour commuting in the Netherlands: gender-specific household activities and personal attitudes towards responsibility sharing. Travel Behav. Soc. 4, 79-87 (2016). https ://doi.org/10.1016/j.tbs.2015.10.003

Pfaff, S.: Pendeln oder umziehen? Mobilitätsentscheidungen in Deutschland zwischen 2000 und 2009. Zeitschrift für Soziologie 41(6), 458-477 (2012)

Pfaff, S.: Pendelentfernung, Lebenszufriedenheit und Entlohnung: Eine Längsschnittuntersuchung mit den Daten des SOEP von 1998 bis 2009. Zeitschrift für Soziologie 43(2), 113-130 (2014)

Potter, S., Enoch, M., Rye, T., Black, C., Ubbels, B.: Tax treatment of employer commuting support: an international review. Transp. Rev. 26(2), 221-237 (2006)

R Core Team: R: A Language and Environment for Statistical Computing. R Foundation for Statistical Computing, Vienna (2019)

Rapino, M.A., Cooke, T.J.: Commuting, gender roles, and entrapment: a national study utilizing spatial fixed effects and control groups. Prof. Geogr. 63(2), 277-294 (2011). https://doi.org/10.1080/00330 124.2010.547790

Reichelt, M., Haas, A.: Commuting farther and earning more? How employment density moderates workers' commuting distance. In: IAB-Discussion Paper, (2015/33), pp. 1-30 (2015)

Renkow, M., Hoover, D.: Commuting, migration, and rural-urban population dynamics. J. Reg. Sci. 40(2), 261 (2000)

Roberts, J., Hodgson, R., Dolan, P.: It's driving her mad: gender differences in the effects of commuting on psychological health. J. Health Econ. 30(5), 1064-1076 (2011)

Rüger, H., Schulze, A.: Zusammenhang von beruflicher Pendelmobilität mit Stresserleben und Gesundheit. Prävention und Gesundheitsförderung 11(1), 27-33 (2016). https://doi.org/10.1007/s11553-015-0521-2 
Rüger, H., Sulak, H.: Wochenendpendeln von Erwerbstätigen in Deutschland: Analysen mit den Mikrozensen 1991 bis 2012. Raumforschung und Raumordnung 75(5), 413-427 (2017). https://doi.org/10.1007/s1314 7-0170496-X

Ruppenthal, S., Lück, D.: Jeder fünfte Erwerbstätige ist aus beruflichen Gründen mobil: berufsbedingte räumliche Mobilität im Vergleich. Informationsdienst Soziale Indikatoren 42, 1-5 (1999)

Sandow, E.: Til work do us part: the social fallacy of long-distance commuting. Urban Stud. 51(3), 526-543 (2014). https://doi.org/10.1177/0042098013498280

Sayer, L.C., Gauthier, A.H., Furstenberg, F.F.: Educational differences in parents' time with children: crossnational variations. J. Marriage Fam. 66(5), 1152-1169 (2004). https://doi.org/10.1111/j.00222 445.2004.00084.x

Scheiner, J.: Randwanderung, Pendeln und Geschlecht in einer polyzentralen Region. Raumforschung und Raumordnung 74(2), 117-134 (2016). https://doi.org/10.1007/s13147-016-0388-5

Scheiner, J., Holz-Rau, C.: Women's complex daily lives: a gendered look at trip chaining and activity pattern entropy in Germany. Transportation 44(1), 117-138 (2017). https://doi.org/10.1007/s11116-015-9627-9

Schleith, D., Widener, M.J., Kim, C., Horner, M.W.: Categorizing urban form for the largest metro regions in the U.S. using the excessive commuting framework. Built Environ. 45(4), 450-461 (2019). https://doi. org/10.2148/benv.45.4.450

Schleith, D., Horner, M.W.: Commuting, job clusters, and travel burdens. Transp. Res. Rec. J. Transp. Res. Board 2452(1), 19-27 (2014). https://doi.org/10.3141/2452-03

Schleith, D., Widener, M., Kim, C.: An examination of the jobs-housing balance of different categories of workers across 26 metropolitan regions. J. Transp. Geogr. 57, 145-160 (2016). https://doi.org/10.1016/j.jtran geo.2016.10.008

Schneider, N.F., Limmer, R., Ruckdeschel, K.: Mobil, flexibel, gebunden: Familie und Beruf in der mobilen Gesellschaft. Campus-Verl, Frankfurt/Main (2002)

Shearmur, R., Motte, B.: Weak ties that bind. Urban Aff. Rev. 44(4), 490-524 (2009). https://doi. org/10.1177/1078087408322592

Strambach, S., Kohl, H.: Mobilitätsdynamiken und Wissensarbeit - zum Wandel berufsbedingter zirkulärer Mobilität. Raumforschung und Raumordnung 73(4), 257-268 (2015). https://doi.org/10.1007/s1314 7-015-0355-6

Stutzer, A., Frey, B.: Commuting and life satisfaction in Germany. Informationen zur Raumentwicklung 3(2), 1-11 (2007)

Stutzer, A., Frey, B.: Stress that doesn't pay: the commuting paradox. Scand. J. Econ. 110(2), 339-366 (2008). https://doi.org/10.1111/j.1467-9442.2008.00542.x

Suedekum, J.: Increasing returns and spatial unemployment disparities. Pap. Reg. Sci. 84(2), 159-181 (2005). https://doi.org/10.1111/j.1435-5957.2005.00011.x

Sultana, S.: Job/housing imbalance and commuting time in the Atlanta Metropolitan Area: exploration of causes of longer commuting time. Urban Geogr. 23(8), 728-749 (2002)

Sultana, S.: Commuting constraints of black female workers in atlanta: an examination of the spatial mismatch hypothesis in married-couple, dual-earner households. Southeast. Geogr. 43(2), 249-259 (2003)

Sultana, S.: Effects of married-couple dual-earner households on metropolitan commuting: evidence from the Atlanta Metropolitan Area. Urban Geogr. 26(4), 328-352 (2005). https://doi. org/10.2747/0272-3638.26.4.328

Surprenant-Legault, J., Patterson, Z., El-Geneidy, A.M.: Commuting trade-offs and distance reduction in two-worker households. Transp. Res. Part A: Policy Pract. 51, 12-28 (2013). https://doi.org/10.1016/j. tra.2013.03.003

Suzuki, T., Lee, S.: Jobs-housing imbalance, spatial correlation, and excess commuting. Transp. Res. Part A: Policy Pract. 46(2), 322-336 (2012). https://doi.org/10.1016/j.tra.2011.10.004

Swärdh, J.-E., Algers, S.: Willingness to accept commuting time within the household: stated preference evidence. Transportation 43(2), 219-241 (2016). https://doi.org/10.1007/s11116-014-9573-y

Van Ommeren, J., Rietveld, P., Nijkampb, P.: Job moving, residential moving, and commuting: a search perspective. J. Urban Econ. 46(2), 230-253 (1999)

Vanoutrive, T., van de Vijver, E., van Malderen, L., Jourquin, B., Thomas, I., Verhetsel, A., Witlox, F.: What determines carpooling to workplaces in Belgium: location, organisation, or promotion? J. Transp. Geogr. 22, 77-86 (2012). https://doi.org/10.1016/j.jtrangeo.2011.11.006

Venables, W.N., Ripley, B.D.: Modern Applied Statistics with S, 4th edn. Springer, New York (2002)

Vuk, G., Bowman, J.L., Daly, A., Hess, S.: Impact of family in-home quality time on person travel demand. Transportation 43(4), 705-724 (2016). https://doi.org/10.1007/s11116-015-9613-2

Wagner, M., Mulder, C.H.: Spatial mobility, family dynamics, and housing transitions. KZfSS Kölner Zeitschrift für Soziologie und Sozialpsychologie 67(S1), 111-135 (2015). https://doi.org/10.1007/s1157 7-015-0327-4 
Weber, J., Sultana, S.: Employment sprawl, race and the journey to work in Birmingham, Alabama. Southeast. Geogr. 48(1), 53-74 (2008). https://doi.org/10.1353/sgo.0.0014

Wind, S.: ACTUM WP2: making daily mobility: phase 1 analysis report. English, vol. 74 (2012)

Winkelmann, U.: Manche pendeln weit: Berufspendler im Bundesländervergleich. Statistisches Monatsheft 4, 40-43 (2010)

Wood, B.S., Horner, M.W., Duncan, M., Valdez-Torres, Y.: Aging populations and transit-oriented development: socioeconomic, demographic, and neighborhood trends from 2000 and 2010. Transp. Res. Rec. J. Transp. Res. Board 2598(1), 75-83 (2016). https://doi.org/10.3141/2598-09

Wrede, M.: Heterogeneous skills, migration, and commuting. Pap. Reg. Sci. 92(2), 345-360 (2013). https://doi. org/10.1111/j.1435-5957.2012.00471.x

Yang, J.: Policy implications of excess commuting: examining the impacts of changes in US metropolitan spatial structure. Urban Stud. 45(2), 391-405 (2008). https://doi.org/10.1177/0042098007085969

Ye, R., de Vos, J., Ma, L.: Analysing the association of dissonance between actual and ideal commute time and commute satisfaction. Transp. Res. Part A: Policy Pract. 132, 47-60 (2020). https://doi.org/10.1016/j. tra.2019.10.011

Zarabi, Z., Manaugh, K., Lord, S.: The impacts of residential relocation on commute habits: a qualitative perspective on households' mobility behaviors and strategies. Travel Behav. Soc. 16, 131-142 (2019). https ://doi.org/10.1016/j.tbs.2019.05.003

Zhou, J., Murphy, E.: Day-to-day variation in excess commuting: an exploratory study of Brisbane, Australia. J. Transp. Geogr. 74, 223-232 (2019). https://doi.org/10.1016/j.jtrangeo.2018.11.014

Zhu, Z., Li, Z., Chen, H., Liu, Y., Zeng, J.: Subjective well-being in China: how much does commuting matter? Transportation 46(4), 1505-1524 (2019). https://doi.org/10.1007/s11116-017-9848-1

Publisher's Note Springer Nature remains neutral with regard to jurisdictional claims in published maps and institutional affiliations.

Moritz Kersting Studied Economics at the University of Göttingen and Halle. Trainee in the office of the member of parliament Mark Helfrich. Visiting researcher at the Max Planck Institute for Dynamics and Self-Organization (MPI DS ) at the Department of Complex Fluids (DCF) in the Next Generation Mobility Group (NGM).

Eike Matthies Studied Geography at the University of Göttingen and Regional Management and Business Development at the Applied University of Science and Arts in Göttingen (HAWK). Visiting researcher at the Max Planck Institute for Dynamics and Self-Organization (MPI DS) at the Department of Complex Fluids (DCF) in the Next Generation Mobility Group (NGM). PhD Student in the Göttingen Graduate School of Social Sciences (GGG) at the Chair of Economic Policy and Small- and medium-sized enterprises.

Prof. Dr. Jörg Lahner Studied Economics at the University of Göttingen, Hanover and Madrid. PhD at the Institute for Small- and medium-sized enterprises (IFH) at the University of Göttingen. Professor at the Applied University of Science and Arts Göttingen (HAWK) in Business Promotion and Regional Economics.

Dr. Jan Schlüter Studied Economics and Physics at the University of Göttingen, the Eötvös University in Budapest and the Copenhagen Business School. Diploma thesis at the Department of Materials Physics at the Eötvös University in Budapest. Max-Planck-Society Scholarship at the Max Planck Research Group (MPRG) of Complex Dynamics and Turbulence. Researcher at the Nonlinear Dynamics and Turbulence Group at the Institute of of Science and Technology Austria (IST Austria). Next Generation Mobility Group (NGM) Leader at the Department of Complex Fluids (DCF) in the Max Planck Institute for Dynamics and Self-Organization (MPI DS). 